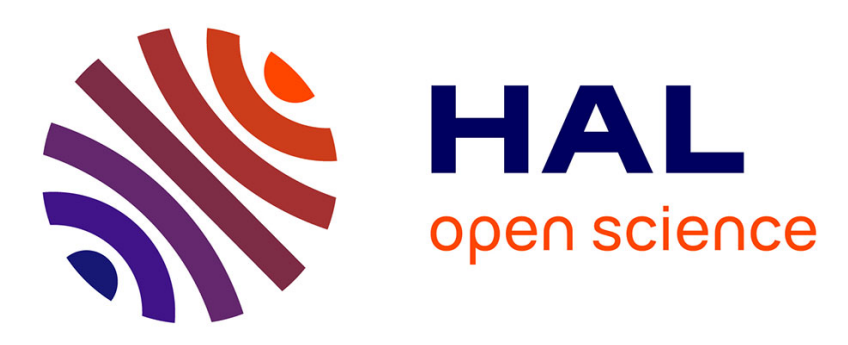

\title{
Creep flow and fracture behavior of the oxygen-enriched alpha phase in zirconium alloys
}

\author{
Raphael Chosson, Anne-Françoise Gourgues-Lorenzon, V. Vandenberghe, \\ Jean-Christophe Brachet, Jérôme Crépin
}

\section{To cite this version:}

Raphael Chosson, Anne-Françoise Gourgues-Lorenzon, V. Vandenberghe, Jean-Christophe Brachet, Jérôme Crépin. Creep flow and fracture behavior of the oxygen-enriched alpha phase in zirconium alloys. Scripta Materialia, 2016, 117, pp.20-23. 10.1016/j.scriptamat.2016.02.021 . hal-01288691

\section{HAL Id: hal-01288691 \\ https: / hal-mines-paristech.archives-ouvertes.fr/hal-01288691}

Submitted on 15 Mar 2016

HAL is a multi-disciplinary open access archive for the deposit and dissemination of scientific research documents, whether they are published or not. The documents may come from teaching and research institutions in France or abroad, or from public or private research centers.
L'archive ouverte pluridisciplinaire HAL, est destinée au dépôt et à la diffusion de documents scientifiques de niveau recherche, publiés ou non, émanant des établissements d'enseignement et de recherche français ou étrangers, des laboratoires publics ou privés. 


\title{
Creep flow and fracture behavior of the oxygen-enriched alpha phase in zirconium alloys
}

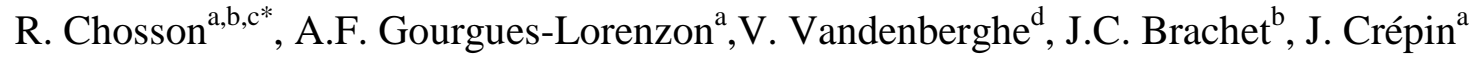 \\ ${ }^{a}$ MINES ParisTech, PSL Research University, Centre des Matériaux, UMR CNRS 7633, BP \\ 87, 91003, Evry Cedex, France \\ ${ }^{\mathrm{b}}$ CEA Saclay, DEN/DMN/SRMA, 91191 Gif-sur-Yvette Cedex, France \\ ${ }^{c}$ (Now at) Areva NP, E\&P Division, 10 rue Juliette Récamier, 69006 Lyon, France \\ ${ }^{\mathrm{d}}$ CEA Saclay, DEN/DMN/SEMI, 91191 Gif-sur-Yvette Cedex, France \\ * Corresponding author. Tel.: +334 72748855 \\ E-mail address: raphael.chosson@areva.com
}

Keywords: zirconium alloys, creep, high temperature deformation, oxidation, embrittlement

\begin{abstract}
During hypothetical Loss-Of-Coolant-Accident (LOCA) scenario, zirconium alloy fuel cladding tubes are exposed to internal pressure and high temperature oxidation, so that an oxygen-stabilized $\alpha(O)$ phase, forms from the outer surface of the cladding, under the zirconia oxide layer. The high-temperature viscoplastic flow and fracture behavior of the $\alpha(O)$ phase was characterized through axial creep tests performed under vacuum, on representative model materials containing 10 - 30 at.\% of oxygen. Creep strengthening and ductile-to-brittle transition were quantified as a function of oxygen content and test temperature, and modelled into viscoplastic flow constitutive equations and an empirical fracture criterion.
\end{abstract}

\section{Introduction}

The hexagonal close-packed alpha $(\alpha)$ phase of Group 4 elements -titanium, zirconium and hafnium- can dissolve up to 30 at.\% interstitial oxygen [1-3]. It exhibits a high chemical affinity for oxygen and in oxidizing environments, an oxygen-stabilized $\alpha$ phase easily forms at high temperature from the body centered cubic $\beta$ phase [4], leading to e.g. the so-called "alpha-case" in Ti alloys. Such high amounts of oxygen deeply alter the mechanical behavior of the $\alpha$ phase and lead to a progressive transition of its mechanical behavior from that of a metal to that of an oxide. In Ti alloys, this phase is very detrimental to ductility, fatigue and creep lifetime up to $600^{\circ} \mathrm{C}$ [5]. The oxygen-enriched $\alpha$ phase of $\mathrm{Zr}$ alloys, called $\alpha(\mathrm{O})$, is also brittle at room temperature from 0.5 wt.\% oxygen [6]. The high-temperature mechanical behavior of oxygen-enriched $\mathrm{Zr}$ alloys has been reported from compression tests and tensile creep tests [7-9]. A significant increase in the compressive steady-state flow stress with increasing oxygen content has been reported, in a linear [7] or an exponential manner [9], for test temperatures between $750^{\circ} \mathrm{C}$ and $1200^{\circ} \mathrm{C}$ and for amounts of oxygen up to $2 \mathrm{wt} . \%$. From tensile creep tests on Zircaloy-2 and Zircaloy- 4 enriched in oxygen, similar oxygen-induced exponential strengthening of the $\alpha$ phase was reported between 700 and $1400^{\circ} \mathrm{C}$ for contents up to 1.5 wt.\% [10,11]. The following empirical relationship has been proposed to describe such effect:

$$
\dot{\varepsilon}=\dot{\varepsilon}_{0} \exp (-B c)
$$

In Eq. $1, \dot{\varepsilon}_{0}$ and $\dot{\varepsilon}$ are the steady-state viscoplastic strain rates $\left(\mathrm{s}^{-1}\right)$ of an oxygen-free and of an oxygen-enriched material, respectively, for the same values of applied stress and temperature; $C$ is the oxygen concentration (wt.\%) and $B$ is an adjustable material parameter. The value of 
$B$ was set to 3.2 in enriched Zircaloy-4 [10] and to 2.8 in enriched Zircaloy-2 [11]. To the authors' knowledge, the viscoplastic flow behavior for oxygen contents beyond $2 \mathrm{wt} \%$ is still unknown while the solubility of oxygen in $\alpha$ phase can reach $7 \mathrm{wt} . \%$. In addition, the ductility of $\alpha(\mathrm{O})$ containing up to $1.5 \mathrm{wt} \% \mathrm{O}$ has never been reported above $750^{\circ} \mathrm{C}$.

The present study focuses on the viscoplastic flow and fracture behavior of the $\alpha(\mathrm{O})$ phase in a $\mathrm{Zr}$ alloy, to identify viscoplastic flow regimes and, if any, creep ductility temperature and composition ranges between 2 and 5.8 wt. $\% \mathrm{O}$ and between 800 and $1100^{\circ} \mathrm{C}$.

\section{Experimental details}

Model oxygen-enriched specimens were produced from as-received $\mathrm{M} 5^{\circledR}(\mathrm{Zr}-1 \% \mathrm{Nb}-0.14 \% \mathrm{O})$ alloy thanks to a two-step procedure. The specimens were $265-\mathrm{mm}$-long tubes with $9.5 \mathrm{~mm}$ in outer diameter and $0.57 \mathrm{~mm}$ in thickness. They were first oxidized in steam in the EDGAR facility [12] in order to add the required 2 (10), 3.2 (16), 4.3 (20) and 5.8 (26) wt.\% (at.\%) oxygen content to the material, mainly as zirconia and $\alpha(\mathrm{O})$ phase outer layers of a few tens of $\mu \mathrm{m}$ in thickness. Oxidized specimens were then fitted to an electro-mechanical tensile machine operated under secondary vacuum and as described by Kaddour et al. [13]. The load was applied along the tube axis. The procedures used for temperature monitoring with spotwelded thermocouples and axial elongation measurement by laser extensometry were the same as in [13].

Annealing the specimens at $1200^{\circ} \mathrm{C}$ under secondary vacuum allowed dissolution of zirconia and diffusion of oxygen across the wall [6], leading to a bulk $\alpha(0)$ microstructure by transformation from the $\beta$ phase. Due to the high temperature oxidation / annealing heattreatment, the produced model materials strongly differ from the original M5 ${ }^{\circledR}$ alloy and consequently will be called $\mathrm{Zr}-1 \% \mathrm{Nb}-c \% \mathrm{O}$ hereafter, where $c$ is the oxygen concentration in wt. $\%$.

Right after the annealing stage, the temperature was decreased down to the value selected for the creep test (Figure 1a), thus avoiding going down to room temperature, at which the $\alpha(\mathrm{O})$ phase is brittle. Several constant load levels were successively applied to a given specimen as in [13]. For each load level, the steady-state true strain rate was measured. None or very limited primary creep was observed. Tests were performed between 800 and $1000^{\circ} \mathrm{C}$ for true axial stresses between 2 and $31 \mathrm{MPa}$. The influence of the loading history was checked to be negligible (within the experimental uncertainties) by increasing, then decreasing load levels on one specimen.

From tested specimens, samples were extracted, polished and etched using in-house preparation procedures [14] and observed by optical and scanning electron microscopy (SEM). Oxygen quantification was systematically done on each tested specimen, using electron probe microanalysis (EPMA), with a $\pm 0.1 \mathrm{wt} \%$ accuracy thanks to an in-house procedure for correction of oxygen contamination artefacts [14]. The average texture was determined by neutron diffraction on 10 -mm-long samples containing about $10^{6}$ grains.

\section{Experimental results and discussion}

\subsection{Microstructure of the model materials}

As illustrated in Figure 1b, the microstructure of the oxygen-enriched specimens is mainly composed of coarse $\alpha(\mathrm{O})$ grains. Their size (30 to $300 \mu \mathrm{m}$ ) is much larger than that of the starting material $(6 \mu \mathrm{m})$. The amount of untransformed $\beta$ phase during the creep test depends on the test temperature and oxygen content. It reaches $15 \pm 5 \%$ at $1100^{\circ} \mathrm{C}$ in $\mathrm{Zr}-1 \% \mathrm{Nb}-2 \% \mathrm{O}$ and is lower than $10 \%$ for lower test temperatures or higher oxygen contents, in agreement 
with literature, as detailed in [15]. Uniform distribution of oxygen across the wall was confirmed by EPMA, with a variation by less than $15 \%$. The residual regions transformed from $\beta$ phase after final cooling were strongly enriched in $\mathrm{Nb}$ and $\mathrm{Fe}$ but only contained $0.5 \pm 0.2 \mathrm{wt} . \%$ of oxygen. Oxygen-enriched specimens exhibited a strong average texture, different from the one of the as-received alloy. The Kearns parameter along the axial and tangential directions were 0.41 and $0.44 \pm 0.05$ respectively, compared to 0.66 and $0.23 \pm 0.05$ for the as-received alloy.

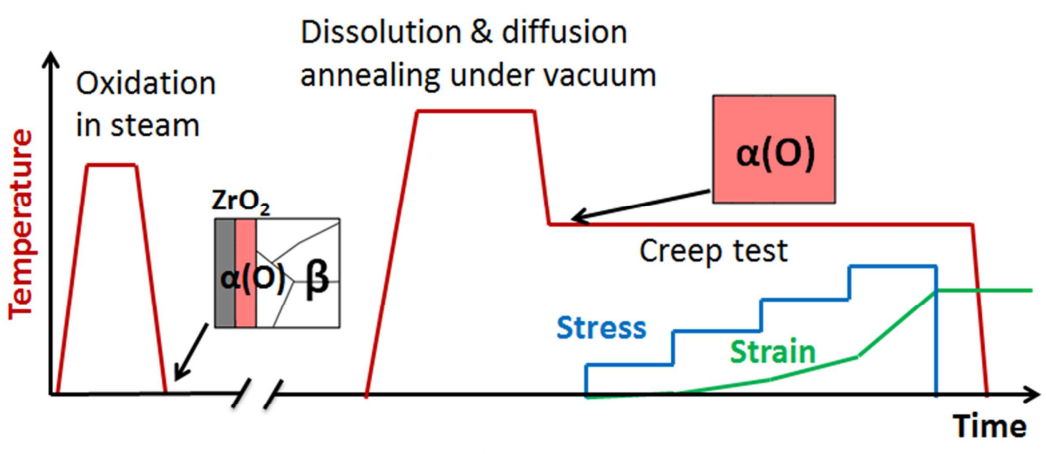

a)

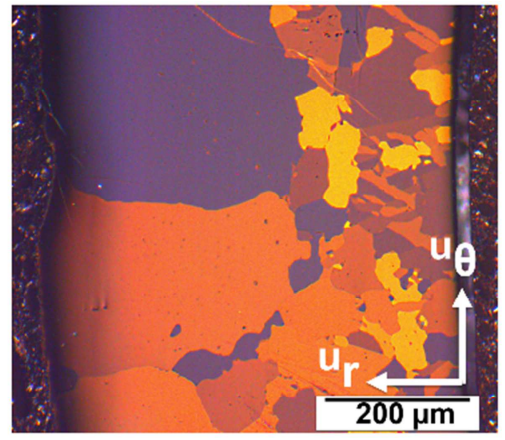

b)

Figure 1: a) Principle of fabrication and thermal-mechanical testing of the $\mathrm{Zr}-1 \% \mathrm{Nb}-\mathrm{c} \% \mathrm{O}$ specimens, with schematic structures of the wall-thickness of the cladding (outer surface on the left), b) Optical micrograph of a $\mathrm{Zr}-1 \% \mathrm{Nb}-3.2 \% \mathrm{O}$ cladding specimen tested at $1000^{\circ} \mathrm{C}$.

\subsection{Viscoplastic flow behavior}

Figure 2 summarizes the viscoplastic flow behavior for 2 and $3.2 \mathrm{wt} . \%$ enriched specimens. A brittle behavior was observed for oxygen content higher than 4 wt.\%, without significant strain. Experimental scattering in strain rates was less than a factor 2 at high stresses and less than $50 \%$ at low stresses.

For the first time, two viscoplastic flow regimes have been evidenced in an oxygen-enriched zirconium alloy. For all temperatures and at higher stresses (> 15 MPa), a typical power-law regime is observed, with a stress power-law exponent, $n$, close to 5. At 1000 and $1100^{\circ} \mathrm{C}$, data at lower stresses $(<10 \mathrm{MPa})$ are consistent with a near-linear flow regime. At $900^{\circ} \mathrm{C}$, data show a transition in the $n$ exponent at lower stresses, possibly to a near-linear regime.

The power-law regime at higher stresses is consistent with viscoplastic strain regimes controlled by glide and climb of dislocations already reported in pure zirconium and its alloys ( $n$ ranging from 4 to $7[13,16,17])$ and in oxygen-enriched zirconium alloys $(n \approx 5.4[10,11])$. The near-linear regime is consistent with diffusional flow regimes, already observed in unenriched $\alpha$ phase at lower temperature $[13,17,18]$. However the average grain size in $\mathrm{Zr}$ $1 \% \mathrm{Nb}-2 / 3.2 \% \mathrm{O}$ is large $(100 \mu \mathrm{m})$ and therefore the near-linear viscoplastic regime could possibly be controlled by a Harper-Dorn mechanism [19]. Materials with various grain sizes should allow ascertaining the actual physical viscoplastic deformation mechanism in these conditions.

Using the creep-rate equations established for un-enriched single phases of two zirconium alloys [13] enables us to point out the strengthening effect of oxygen. This comparison was made despite the difference in texture of both kinds of materials, as the strain anisotropy of the $\alpha$ phase might be low at such high temperatures [19]. As this phase is not stable at high temperature without oxygen addition, its mechanical behavior has to be extrapolated up to $1000^{\circ} \mathrm{C}$ for comparison with the present results. $\mathrm{Zr}-1 \% \mathrm{Nb}-2 / 3.2 \%$ alloys exhibit a much higher resistance to viscoplastic strain $(\mathrm{x} 100$ to $\mathrm{x} 1000)$ than that predicted for the $\alpha$ phase of un-enriched alloys. 


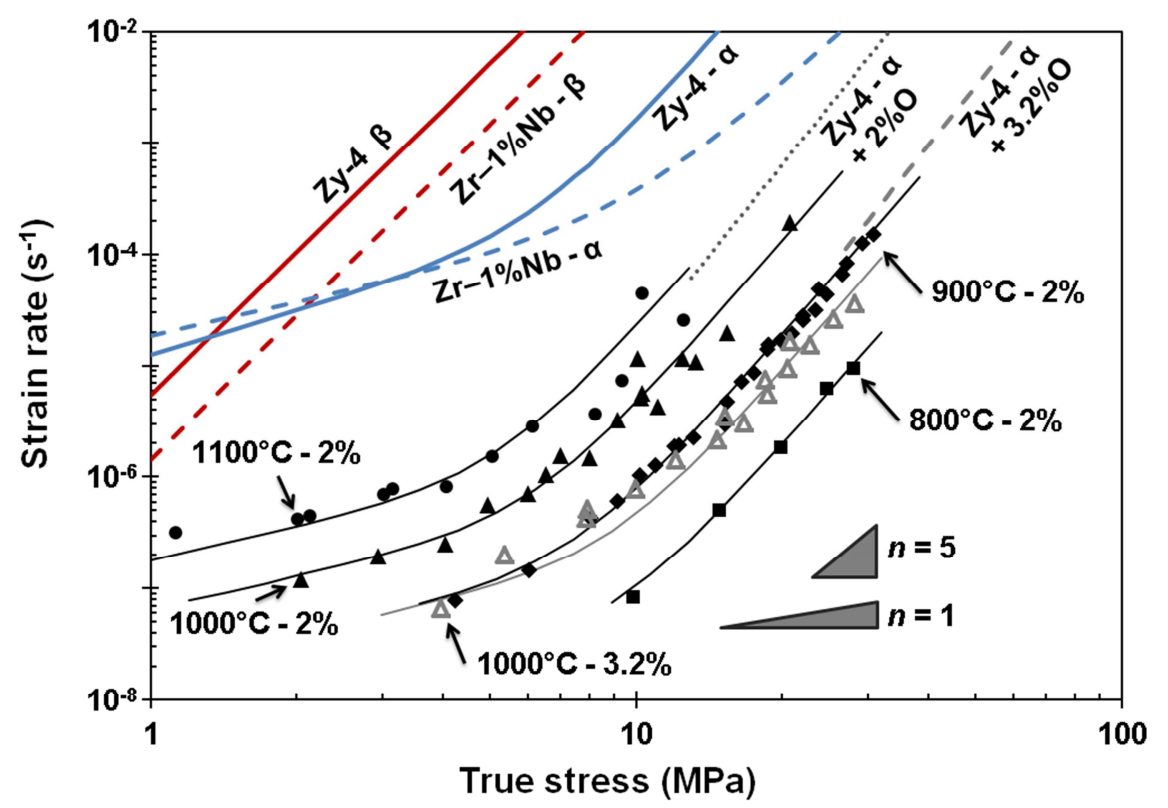

Figure 2: Stress sensitivity of the strain rate: present experimental results on $\mathrm{Zr}-1 \% \mathrm{Nb}-2 \% \mathrm{O}$ alloys (black symbols) and on $\mathrm{Zr}-1 \% \mathrm{Nb}-3.2 \% \mathrm{O}$ alloys (grey symbols), predictions at $1000^{\circ} \mathrm{C}$ for zirconium alloys which are non-enriched (color lines) [13] or enriched with oxygen (dashed and dotted grey lines) [11].

For comparison purposes the creep-rate equations established between 800 and $1000^{\circ} \mathrm{C}$ by Chow et al. [11] on up to $1.5 \mathrm{wt} . \%$ oxygen-enriched Zircaloy-4 were extrapolated to higher oxygen contents. In the higher stress domain, strain rate predictions obtained in this way are five times higher than those measured for $\mathrm{Zr}-1 \% \mathrm{Nb}-2 \% \mathrm{O}$ but are close to the ones obtained for $\mathrm{Zr}-1 \% \mathrm{Nb}-3.2 \% \mathrm{O}$. Because of the transition to a near-linear viscoplastic regime, strain rate predictions based on the results of Chow et al. are not relevant in the lower stress regime.

Power-law equations of the following form were used to describe the two viscoplastic strain regimes observed in $\mathrm{Zr}-1 \% \mathrm{Nb}-2 \% \mathrm{O}$ :

$$
\dot{\varepsilon}=\frac{A}{T} \exp \left(\frac{-Q}{R T}\right) \sigma^{n}
$$

In Eq. 2, $\sigma$ and $T$ are the applied true stress (MPa) and the test temperature (K) respectively. $A, Q$, and $n$ are material parameters. In order to increase the number of data for the near-linear regime, the results at $1100^{\circ} \mathrm{C}$ were also used, although the fraction of untransformed $\beta$ phase was still significant. In that case, the softening contribution of the $\beta$ phase was estimated to a first order homogenization approach, by using a Taylor-based assumption and the creep-rate equation of the $\mathrm{Zr}-1 \% \mathrm{Nb}-\mathrm{O}$ [13] to describe the $\beta$ phase. Strengthening brought by enrichment of the $\beta$ phase in $\mathrm{Nb}$ and of the $\alpha$ phase in oxygen was also estimated, according to [21] and [11] respectively. Following this approach, both strengthening and softening effects were found to be small (less than a factor of 2 on the strain rate) and to compensate each other [20]. The identified values of material parameters are given in Table 1. Values of activation energy $Q$ are comparable with those reported in non-enriched $\mathrm{Zr}-1 \% \mathrm{Nb}-0.14 \% \mathrm{O}$ for the both regimes [13]. The difference between model predictions and experimental results is within the experimental scatter. 


\begin{tabular}{lcc} 
Strain regime & $\begin{array}{c}\text { Near-linear } \\
1<\sigma<15 \mathrm{MPa}\end{array}$ & $\begin{array}{c}\text { Power-law } \\
15<\sigma<31 \mathrm{MPa}\end{array}$ \\
\hline$A\left({\left.\mathrm{~K} . \mathrm{s}^{-1} . \mathrm{MPa}^{-5}\right)}^{-5}\right.$ & $2.03 \times 10^{3}$ & 47.0 \\
$Q\left(\mathrm{~kJ} . \mathrm{mol}^{-1}\right)$ & 180 & 222 \\
$n$ & 1 & 5 \\
\hline
\end{tabular}

Table 1: Flow parameters of $\mathrm{Zr}-1 \% \mathrm{Nb}-2 \% \mathrm{O}$ in the two viscoplastic strain regimes.

In order to investigate the strengthening effect of oxygen in more detail, literature data from tensile creep tests $[10,11,13]$ and compression tests [8,9] were put together with the present results on $\mathrm{Zr}-1 \% \mathrm{Nb}-2 / 3.2 \% \mathrm{O}$ in Figure 3. The large scatter in activation energy and stress exponent reported for oxygen-enriched as well as for un-enriched $\mathrm{Zr}$ alloys does not allow the investigation of any effect of oxygen on these parameters. Consequently, only an effect of the oxygen content on parameter $A$ is considered here, so that $Q$ and $n$ are assumed to be independent of the oxygen content (see Equation 2), in agreement with our results.

For all tests, the steady-state strain rate was normalized by the steady-state stress. All literature data come from tests at high stresses (10-130 MPa), so that previously identified value of $n \approx 5$ was used for stress normalization. All data were obtained at $800^{\circ} \mathrm{C}$ with the exception of data from Tseng and Tangri [8] obtained at $850^{\circ} \mathrm{C}$ and the creep results on $\mathrm{Zr}$ $1 \% \mathrm{Nb}-3.2 \% \mathrm{O}$ obtained at $1000^{\circ} \mathrm{C}$ in the present study. For both of them, a temperature correction was applied using the activation energy $Q$ of the higher stress regime, given in Table 1.

Normalized strain rates in compression are consistently lower by one order of magnitude than those in tension. This could be related to a strength differential of the material between tension and compression loadings. The differences in chemistry and microstructure between the considered as-received Zr-1\% Nb-O, Zircaloy- 2 and Zircaloy-4 alloys result in a factor 3 discrepancy in strain rates. Whatever the kind of test, an exponential strengthening by oxygen is noticed. The oxygen sensitivity $B$ (Eq. 1$)$ appears higher in compression $(B \approx 2.7)$ than in tension $(B \approx 2.4)$. The latter value is significantly lower than those reported by Chow et al. (2.8) [11] and Burton et al. (3.2) [10].

By only considering the data on $\mathrm{Zr}-1 \% \mathrm{Nb}-0.14 \% \mathrm{O}$ [13] and the present results on $\mathrm{Zr}-1 \% \mathrm{Nb}-$ $2 \% \mathrm{O}$, the viscoplastic strain rates in the higher stress regime can accurately be reproduced by combining Equations 1 and 2 into following Equation 3, with $A^{\prime}=4.80 \times 10^{3} \mathrm{~K}^{-1}{ }^{-1} \cdot \mathrm{MPa}^{-}$ ${ }^{5}, Q=222 \mathrm{~kJ} \cdot \mathrm{mol}^{-1}, n=5$ and $B \approx 2.3$.

$$
\dot{\varepsilon}=\frac{A^{\prime}}{T} \exp \left(\frac{-Q}{R T}\right) \sigma^{n} \exp (-B c)
$$




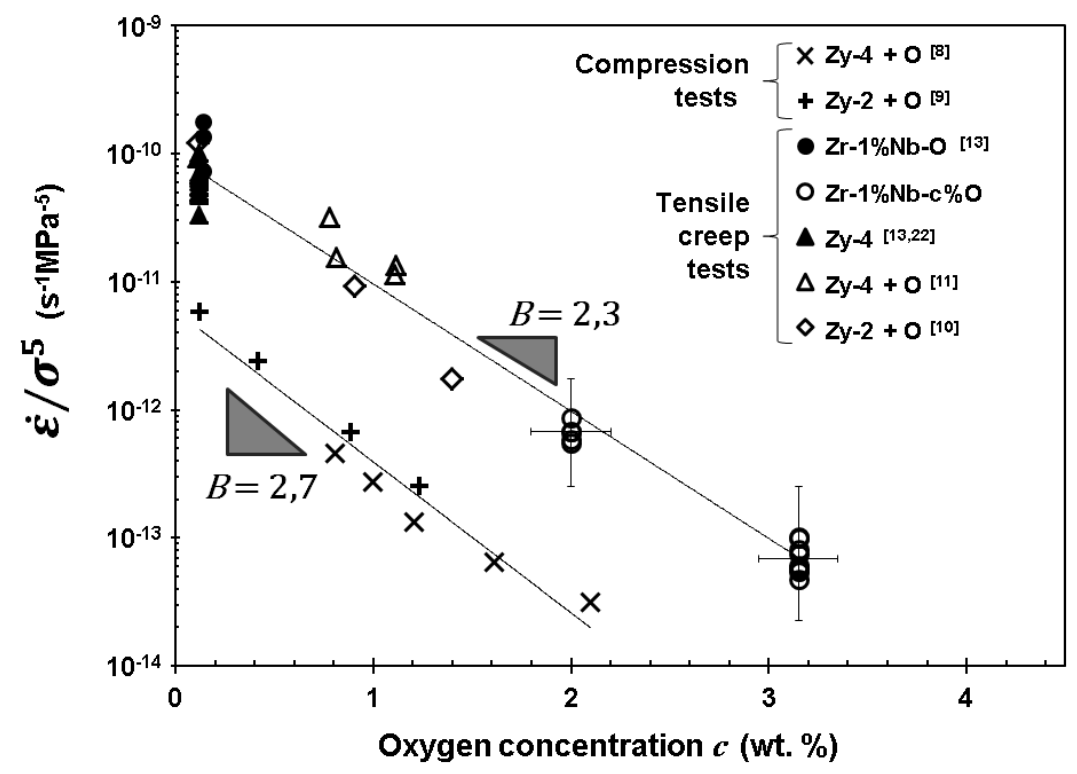

Figure 3: Normalized strain rate as a function of oxygen concentration in the $\alpha$ phase: comparison with literature data.

\subsection{Creep fracture behavior}

Significant strain levels were reached during creep tests between 800 and $1100^{\circ} \mathrm{C}$ on $\mathrm{Zr}$ $1 \% \mathrm{Nb}-2 \% \mathrm{O}$ and $\mathrm{Zr}-1 \% \mathrm{Nb}-3.2 \% \mathrm{O}$ specimens. Due to limitations in elongation allowed by the extensometry device, not all tests were carried out to fracture but at least $4 \%$ axial strain was reached in each case. For $\mathrm{Zr}-1 \% \mathrm{Nb}-2 \% \mathrm{O}$, a $15 \%$ axial strain was reached during a creep test at $900^{\circ} \mathrm{C}$ without failure. For the same material at $1000^{\circ} \mathrm{C}$ a $22 \%$ axial strain was measured in the necking region of a broken specimen by using laser profilometry. SEM observations of the fracture surface revealed local reduction in thickness by almost $100 \%$ all over the fracture surface (Figure 4). Some dimples were also observed. During the creep test performed on $\mathrm{Zr}$ $1 \% \mathrm{Nb}-3.2 \% \mathrm{O}$ at $1000^{\circ} \mathrm{C}, 10 \%$ axial strain was reached without failure. For 4.3 and 5.8 wt.\% $\mathrm{O}$, a purely brittle behavior was observed above $1000^{\circ} \mathrm{C}$ with fracture surfaces showing mixed cleavage and intergranular fracture (Figure 4).

From these results, materials oxygen-enriched up to 2-3.2 wt. $\%$ are ductile at high temperature (above $800-1000^{\circ} \mathrm{C}$ ) but those with higher oxygen contents are brittle. On the one hand, Tseng and Tangri [8] already obtained strains higher than $8 \%$ in compression tests between 850 and $1100^{\circ} \mathrm{C}$ on 1.8 wt. \% oxygen-enriched alpha phase, even though compression tests are less challenging than tensile tests regarding fracture. On the other hand, oxygen-enriched Zircaloy- 4 is brittle at low temperature $\left(<200^{\circ} \mathrm{C}\right)$ for oxygen contents as low as 0.5 wt. \% [6,23].

Based on our observations and on data available from literature [6-11,23,24] and using a methodology detailed in [20], a summary view of the ductile-to-brittle transition (DBT) in the $\alpha$ phase of oxygen-enriched zirconium alloys is proposed in Figure 4 . The DBT is a function of both temperature and oxygen content. The higher the oxygen content, the higher the DBT temperature. For a given oxygen content, $c$, the DBT temperature, $T_{c}$ can satisfactorily be empirically described by Equation 4:

$$
c=\left(1.2 \times 10^{-6}\right) T_{c}^{2}+\left(1.8 \times 10^{-3}\right) T_{c}+5.7
$$

The increase in $T_{c}$ with increasing oxygen content might be due to effects of interstitial oxygen in $\mathrm{Zr}$ alloys (e.g. ordering at lower temperature [25], change in the strength or the nature of $\mathrm{Zr}-\mathrm{O}$ bonds for high oxygen contents). The underlying mechanism is yet still unclear, especially at high temperatures, and requires further investigation. 

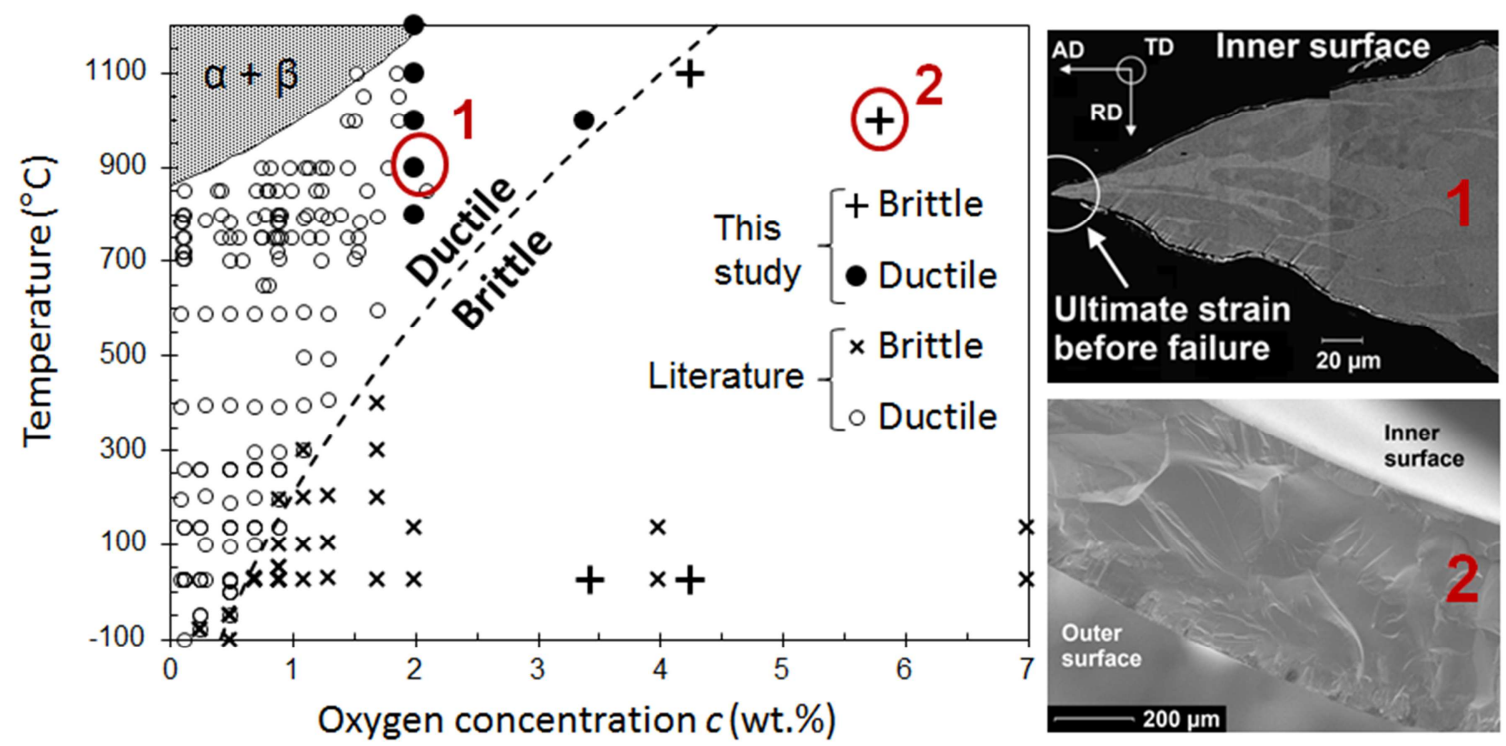

Figure 4: Ductile-to-brittle transition in zirconium alloys as a function of temperature and oxygen concentration, data from this study and from literature [6-11,23,24]. Fracture of $\mathrm{Zr}$ $1 \% \mathrm{Nb}-2 \% \mathrm{O}$ (longitudinal section) and of $\mathrm{Zr}-1 \% \mathrm{Nb}-5.8 \% \mathrm{O}$ (fracture surface) after tensile creep. Comparison with prediction from Eq. 4 (dashed line).

\section{Conclusion}

$\mathrm{Zr}-1 \% \mathrm{Nb}-\mathrm{c} \% \mathrm{O}$ alloys with homogenous oxygen distribution were produced in order to investigate the strengthening effect of high oxygen contents. From axial tensile creep tests between 800 and $1100^{\circ} \mathrm{C}$, these alloys exhibit a high resistance to viscoplastic deformation and the following results were obtained:

- For the first time, two viscoplastic strain regimes have been observed in oxygenenriched alloys: a near-linear regime for stresses under $10 \mathrm{MPa}$ and a power-law regime for stresses above $15 \mathrm{MPa}$.

- The modeling of oxygen strengthening by an exponential multiplicative factor - already established for oxygen contents lower than $1.5 \mathrm{wt} . \%$ - can be successfully extended up to $3.2 \mathrm{wt}$. \% with similar parameters.

- Above $800^{\circ} \mathrm{C}$, oxygen-enriched $\mathrm{Zr}-1 \% \mathrm{Nb}-2 / 3.2 \% \mathrm{O}$ alloys are highly ductile. A $10 \%$ axial strain before failure was reached in $\mathrm{Zr}-1 \% \mathrm{Nb}-3.2 \% \mathrm{O}$ at $1000^{\circ} \mathrm{C}$. At $1000^{\circ} \mathrm{C}, \mathrm{Zr}-$ $1 \% \mathrm{Nb}-4.3 / 5.8 \% \mathrm{O}$ specimens are brittle and fail by mixed cleavage and intergranular fracture.

- A ductile-to-brittle transition, expressed as a simple function of both temperature and oxygen content has been established for oxygen-enriched zirconium alloys.

\section{Acknowledgments}

AREVA NP and EDF are gratefully acknowledged for providing the material, for fruitful discussions and for funding. The authors would also like to thank D. Hamon, V. Lezaud, E. Rouesne and S. Urvoy from the CEA, and J. Heurtel and A. Laurent from the Centre des Matériaux for their contribution to this work.

\section{References}

[1] H. Okamoto, J. Phase Equilib. Diff. 32 (2011) 473-474.

[2] H. Okamoto, J. Phase Equilib. Diff. 28 (2007) 498.

[3] H. Okamoto, J. Phase Equilib. Diff. 29 (2008) 124. 
[4] G.J. Yurek, J.V. Cathcart, R.E. Pawel, Oxidations of Metals 10(4) (1976) 255-276.

[5] R.W. Evans, R.J. Hull, B. Wilshire, J. Mater. Process. Tech. 56 (1996) 492-501.

[6] A. Stern, PhD Thesis, Ecole des Mines de Paris, (in French) 2008.

[7] A.S. Rizkalla, R.A. Holt, J.J. Jonas, ASTM STP 681 (1979) 497-513.

[8] D. Tseng, K. Tangri, Metall. Mater. Trans. A 13A (1982) 1077-1082.

[9] R. Choubey, J.J. Jonas, R.A. Holt, C.E. Ells, ASTM STP 754 (1982) 350-369.

[10] B. Burton, A.T. Donaldson, G.L. Reynolds, ASTM STP 681 (1979) 561-585.

[11] C.K. Chow, H.E. Rosinger and P.C. Bera, Materials in Nuclear Energy, Huntsville, Canada, (1982).

[12] T. Forgeron, J. Brachet, F. Barcelo, A. Castaing, J. Hivroz, J. Mardon and C. Bernaudat, ASTM STP 1354 (2000) 256-278.

[13] D. Kaddour, S. Fréchinet, A.F. Gourgues, J.C. Brachet, L. Portier, A. Pineau, Scripta Mater. 5 (2004) 515-519.

[14] J.C. Brachet, V. Vandenberghe-Maillot, L. Portier, D. Gilbon, A. Lesbros, N. Waeckel, J.P. Mardon, J. ASTM Int. 5 (2008).

[15] R. Chosson, V. Vandenberghe, A.F. Gourgues, J. Crépin, J.C. Brachet, A. Cabrera, V. Garat, LWR fuel performance meeting Topfuel 2013, Charlotte, US, (2013).

[16] T.A. Hayes, M.E. Kassner, Metall. Mater. Trans. A 37A (2006) 2389-2396.

[17] B. Kombaiah and K. Linga Murty, Philos. Mag. 95 (2015) 1656-1679.

[18] P. Rama-Rao, Curr. Sci. 75 (1998) 564-579.

[19] J. Novotny, J. Fiala, J. Cadek, Acta Metall. 33 (1985) 905-911.

[20] R. Chosson, PhD Thesis, MINES Paristech (in french) 2014.

[21] G. Trego, PhD Thesis, MINES Paristech, (in french) 2011.

[22] S. Fréchinet, PhD Thesis, MINES Paristech, (in french) 2001.

[23] S. Sawatzky, ASTM STP 681 (1979) 479-496.

[24] A. M. Garde and H. M. Chung, ANL-77-30, Argonne national laboratory 1977.

[25] T. Tsuji and M. Amaya, J. Nucl. Mat. 223 (1995) 33-39. 